\title{
A Review on Studies into Incidental Vocabulary Acquisition through Different Input
}

\author{
Zhongqing Tang ${ }^{1}$ \\ ${ }^{1}$ Faculty of English Language and Literature, Guangdong University of Foreign Studies, Guangzhou, China \\ Correspondence: Zhongqing Tang, Faculty of English Language and Literature, Guangdong University of Foreign \\ Studies, Guangzhou, China. E-mail: tangzqce@163.com
}

Received: March 31, 2020

Accepted: May 18, 2020

Online Published: May 19, 2020

doi: 10.5539/elt.v13n6p89

URL: https://doi.org/10.5539/elt.v13n6p89

\begin{abstract}
Vocabulary acquisition, after being neglected for centuries, aroused people's attention from the second half of last century. At that time, people began to realize, instead of grammar, vocabulary occupies the central role in language acquisition (Gass \& Selinker, 1994). Compared with intentional vocabulary acquisition, incidental vocabulary acquisition was found to be the major way for people to acquire vocabularies. Early studies into incidental vocabulary acquisition focused on incidental vocabulary acquisition through reading activities. Later on, people found that listening activities was another good way to enhance incidental vocabulary acquisition. Nowadays, task mode of incidental vocabulary acquisition has become more pluralistic than before. This article is to review studies into incidental vocabulary acquisition through different input and point out the limitations of previous studies. The first limitation of previous studies is that word knowledge framework was undefined in previous studies and the second limitation is that prior knowledge, an factor which needs to be controlled, was neglected by some scholars. This review will hopefully provide some suggestions for both language teachers and language learners.
\end{abstract}

Keywords: incidental vocabulary acquisition, task mode, language teaching, word knowledge framework

\section{Introduction}

Before discussing incidental vocabulary acquisition, one needs to know the importance of vocabulary in language acquisition. Vocabulary acquisition was found to be a crucial part in language acquisition since the second half of last century. Wilkins (1972) concluded that one couldn't express many things without grammar, but one could express nothing without vocabulary. By the end of the last century, most researchers have diverted their focus from grammar to vocabulary. Since vocabulary acquisition is crucial to language acquisition, then how do people acquire vocabulary? To explore how people acquire vocabularies, Nagy (1985) conducted an experiment, researching child vocabulary acquisition, to reveal the core mechanism of vocabulary acquisition since the average rate for children to acquire vocabulary was several thousand per year and most vocabularies were acquired incidentally instead of intentionally. This study identified that incidental vocabulary acquisition accounts for a substantial proportion of the vocabulary growth for children. Vocabulary in second language, which is similar to that of first language, could be acquired incidentally (Dupuy \& Krashen, 1993; Ellis \& He, 1999; Webb, 2007). And Laufer (2003) proposed that incidental vocabulary acquisition is the learning of vocabulary as a by-product of an activity which is with the purpose of explicit lexical learning. This definition pointed out that vocabulary could be incidentally acquired via any activity aiming at explicit lexical learning, which is not limited to meaning-focused communicative activities.

As is stated in the preceding part, vocabulary has replaced the role of grammar and gradually became a crucial topic in language acquisition. Early studies into incidental vocabulary acquisition mainly studied the effects of reading task (see e.g. Pellicer-Sánchez, 2014; Rott, 1999; Webb, 2007). Later on, researchers studied the effects of incidental vocabulary acquisition through assorted activities, such as listening (see e.g. Vidal, 2003), TV watching and gaming (see e.g. Ina, 2014). Thus, this paper is to review the effects of different input on incidental vocabulary acquisition and try to figure out the research trend. In addition, the standard of lexical knowledge by different experiment and whether researchers need to control participants' prior knowledge have resulted in nuanced questions, which will also be discussed in this paper. Finally, a conclusion will be presented. 


\section{Incidental Vocabulary Acquisition through Different Input}

Early studies mainly concentrate on incidental vocabulary acquisition through reading. Gradually, listening was considered a way to enhance vocabulary acquisition in reading activity, which lay the foundation for later study on listening-only task. In recent years, task mode of incidental vocabulary acquisition, becoming more pluralistic than before, is not restricted in traditional classroom activities such as reading and listening. Nowadays, more modern and high-tech tasks have been applied in the study of incidental vocabulary acquisition. This part is to review studies on incidental vocabulary acquisition, with its focus on the development of task mode.

\subsection{Incidental Vocabulary Acquisition through Reading}

Most studies into incidental vocabulary acquisition have been conducted to examine and verify the effect of reading task in the early stages (see e.g. Joe, 1995; Rott, 1999). During reading, learners can incidentally acquire remarkable amount of lexicon knowledge even though no instruction is given to draw learners' attention to vocabularies. Reading materials in previous studies vary from test to sentences and reading materials of different genres were all proved to be effective in facilitating incidental vocabulary acquisition.

For example, Rott (1999) designed a study to examine whether learner can incidentally acquire and retain vocabulary knowledge through reading input, in which both receptive and productive vocabulary knowledge were tested, and found that most vocabulary knowledge could be acquired after two encounters in the reading task. The majority of studies in the 20th century on incidental vocabulary acquisition through reading focused on a single test genre (see e.g. Day, Omura \& Hiramatsu, 1991; Dupuy \& Krashen, 1993). But various test genres, including short test, short story, novel and so on, haven been shown in some studies to be beneficial for inducing vocabulary acquisition incidentally (see e.g. Rott, 1999; Saragi, Nation \& Meister, 1978). Similarly, Gardener (2004) compared the lexical difference between narrative and expository reading materials, shedding lights on the effect of task genre on incidental vocabulary acquisition and debunking the deficiency of previous studies. After analysing twenty-eight narrative and twenty-eight expository children's books, Gardener (2004) found the potential for protracted vocabulary growth existing at different levels of vocabulary. In addition, narrative was found to better facilitate general frequency words acquisition, which expository was better for academic high frequency and unique words acquisition. This study provided an insightful and thought-provoking analysis of the effect of task genre on incidental vocabulary acquisition, but failed to take more task genre into consideration. Thus future study can focus on the effect of different test genre on vocabulary acquisition

In addition, the test of reading task studied was relatively short in last century. Under this condition, Reynolds (2015) gained a more nuanced insight into incidental vocabulary acquisition by investigating fiction reading task. Findings of this research suggested that both English-L1 and English-L2 learners could incidentally acquire vocabulary through reading fiction and the acquisition could be enhanced if the fiction is enjoyable. Apart from these studies, Folse (2006) and Bao (2015) both proved that sentences, another kind of reading material, could also facilitate incidental vocabulary acquisition.

Till today, studies into incidental vocabulary acquisition through reading have examined the effect of different reading materials and mostly proved that vocabulary can be incidentally acquired through reading input. Bedsides these studies considering the effect of reading task on incidental vocabulary acquisition, there are, however, areas in which other variables are examined by the aid of reading task(e.g., Waring \& Nation 2004; Webb 2008). For example, Teng (2019) studies the effects of context and the frequency of word occurrence on incidental vocabulary acquisition through reading task offered another confirmation of the effect of reading on incidental vocabulary acquisition.

To summarise, studies on incidental vocabulary acquisition have generally proved that learners can gain some vocabulary knowledge while doing reading tasks. In addition, various tests genre of reading task and sentences have been identified beneficial for vocabulary acquisition, which implies the trend for pluralistic study. But people gradually found that other tasks might also induce incidental vocabulary acquisition. Reading, along with listening, speaking and writing are the four essential skills in language acquisition. Previous studies mainly investigating incidental vocabulary acquisition through reading, while another noteworthy point which emerges from the analysis is that vocabulary can be incidentally acquired via other activities like listening.

\subsection{Incidental Vocabulary Acquisition through Listening}

As is stated in the preceding part, reading task has been proved to be effective in promoting incidental vocabulary acquisition. Thus language learners can acquire vocabulary knowledge while enhancing reading ability and picking up knowledge. Unlike the results of most studies mentioned in the preceding part, a small part of studies indicated that the number and quality of vocabulary acquired through reading could be limited (Pellicer-Sánchez \& 
Schmitt, 2010; Waring \& Takaki, 2003). In addition, theoretically speaking, listening task, which is similar to reading task since both tasks serve to provide input to learners, ought to be effective in facilitating vocabulary acquisition incidentally.

Under this condition, some scholars began to wonder whether another input mode, listening, can promote vocabulary acquisition incidentally. Since many English learners whose mother tongues are non-Indo-European languages have high ability in reading but suffer from poor hearing, studies in the early 21 th century shed light on incidental vocabulary acquisition through another unheeded input mode: listening with the aim of finding a win-win way to improve listening proficiency as well as induce incidental vocabulary acquisition.

Earlier studies, considering listening, suggested that listening was only a way of enhancing the effect of incidental vocabulary acquisition through reading, offering new thought for future studies. Later on, Brown, Waring \& Donkaewbua (2008) designed an experiment to compare incidental vocabulary acquisition from three input modes: reading, reading-while-listening and listening to stories, suggesting vocabulary could be incidentally acquired in all three modes and and the frequency of word occurrence hold a positive correlation with the immediate acquisition result and retention. Their study revealed that the reading-while-listening task was much better way to facilitate vocabulary acquisition than reading and listening task, but these vocabulary tests, namely a multiple-choice test and a meaning-by-translation test, had limitations in demonstrating increment in vocabulary acquisition in detail. A decade later, Teng (2018) compared the effect of reading-while-listening task with reading-only task on incidental vocabulary acquisition. In his study, 24 Chinese EFL students were enrolled, with their vocabulary size being tested before the experiment, which guaranteed that the results of the experiment would not be affected by participants' prior knowledge. Four dimensions of vocabulary knowledge including form recognition, grammar recognition, meaning recall and collocation recognition were tested to ensure the smallest increment in vocabulary acquisition could be observed. The results indicated that words were acquired more effectively in reading-while-listening task, therefore, proving listening to be a good way to enhance vocabulary acquisition. These two studies mentioned above have much in common since both studies consider listening a way to enhance vocabulary acquisition in reading task. And the better acquisition effect in reading-while-listening task may be that listening materials helps learners to break sentences into small coherent parts and listening input can make learners draw more attention to the task (Amer 1997).

In 2013 , a groundbeaking study by Zeeland and Schmitt offered insightful and thought-provoking analysis of incidental vocabulary acquisition through L2 listening for the reason that it appeared to be the first study to concentrate on listening task only which applied a relative comprehensive vocabulary knowledge framework including form recognition, grammar recognition and meaning recall. Non-words were used in the experiment to guarantee the participants' mastery of target words were equal at the beginning and eliminate external interference factors during the experiment. This study appears to demonstrate that word form was acquired relatively easily through L2 listening, but word meaning was not, resulting from time limitation of listening activity. In addition, Vidal (2011) compared the effect of academic listening with that of academic reading. The results indicated that participants from reading task performed better from various perspectives. At the same time, many other studies have been conducted to investigate the disparity between listening input and reading input, most of which confirmed that reading-only task could better promote incidental vocabulary acquisition than listening-only task (see e.g. Chang \& Ma, 2018).

To summarise, studies on incidental vocabulary acquisition through reading boomed from the beginning of this century. Most studies proved that vocabulary can be incidentally acquired even though the effect of listening task was not so good as reading task. The reason for this phenomenon may be that there's no time limitation in reading task and learners can go back to read as they want, which is not available in listening task. In addition, without a high level of concentration, learners are easily to miss some important parts in listening task, but learners can get absent-minded and stop reading for a while without missing any information in reading tasks. Anyhow, studies on incidental vocabulary acquisition through listening provide a win-win way for learners to acquire lexicon knowledge and improve listening proficiency at the same time.

\subsection{Incidental Vocabulary Acquisition through Other Activities}

The research mentioned above endeavors to both disentangle and elucidate that vocabulary can be acquired incidentally through reading and listening whose aim is not to commit lexical information for learners to remember. Its value lies in not only affirming that vocabulary can be incidentally acquired as a by-product of other activity, but also combining reading, listening task together with vocabulary acquisition, which enables learners to improve reading or listening proficiency and acquire lexical knowledge at the same time. Even though reading task and listening task do provide learners ample vocabulary input and induce incidental vocabulary acquisition, some 
language learners might consider reading and listening a form of learning activity and get bored with these tasks. To fill the gap, recent studies begin to probe into some more modernize way, such as gaming and TV show, to induce incidental vocabulary acquisition.

Reynolds (2017) reported an investigation of incidental vocabulary acquisition through digital gaming, utilizing the easy access and convenience of mobile devices, which led vocabulary acquisition out of classroom environment. Draw Something, a popular social drawing game, was found to be effective to facilitate vocabulary acquisition because of learners' intrinsic motivation to plunge into gaming. Unlike traditional reading or listening activities, this gaming acts as another source of language input, offering vivid pictures and fictitious coin rewards, to make the progress much more enjoyable, which is in accordance with Krashen's Pleasure Hypothesis. This hypothesis, holding a good language acquisition activity needs to be perceived as pleasant by learners instead of painful, shed lights on the studies in recent years.

Similarly, TV program was found to effectively induce vocabulary acquisition at multi-dimensions (Peter \& Webb, 2018). This is the first study to explore incidental vocabulary acquisition through viewing TV program, which has the following advantages: first, TV program provides authentic and spoken L2 input; second, some low frequency lexicons can be acquired via viewing TV program; last but not least, the access for watching TV is easily acquired. The results of this study revealed that learner's ability to recall meaning and recognize meaning could be enhanced and the more ecologically valid the TV program was, the better the acquisition effect would be. Meanwhile, incidental vocabulary acquisition was proved to occur after viewing captioned video, flashing stories and so on (Mousavi \& Gholami, 2014; Jelani \& Boers, 2018).

All in all, with the development of science and technology, ways for people to entertain have become more diverse than before and paper reading and listening are no longer the most important sources for people to get information about the world, thus people are spending more time with their telephone and computer instead of paper reading and listening. Under this condition, recent studies on incidental vocabulary acquisition through activities such as playing digital game and viewing TV program provide an excellent way to induce vocabulary acquisition in the age of high-technology.

\section{Limitation of Previous Studies}

As is stated in the preceding chapter, researchers has acquired fruitful achievements in the study of incidental vocabulary acquisition, giving enlightenment to both language learners and language teachers. Yet, there are some drawbacks in the previous studies. First, the standard of vocabulary knowledge varies a lot from study to study, which make these studies less comparable. Second, prior knowledge, which was found to influence the effect of vocabulary acquisition, was sometimes neglected in some studies. So, this part is to critically analyse these two problems in previous studies and try to figure out a way to to reduce the impact of these two problems in future studies.

\section{Undefined Word Knowledge Framework}

To investigate whether learners have incidentally gain some lexicon knowledge, researchers in every study need to apply a word knowledge framework to examine how much participants have gained from various dimensions. But the standard for studies varies a lot, leading the results of these studies less comparable. So, this part is to critically analyze this problem in previous studies and try to provide some suggestions for future studies.

Due to the lack of a comprehensive word knowledge framework in the early stage of study on incidental vocabulary acquisition, some loose standards were used to examine vocabulary gain. For example, Rott (1999) tested both productive by asking participants to supply word meaning and receptive knowledge by letting participants select the correct word definition from four options to measure vocabulary gain and retention. Even though both receptive and productive knowledge were tested, these two tests both focused on word meaning, a partial of lexicon knowledge, which could not represent vocabulary gain as a whole.

Studies in recent years have applied a more rigor vocabulary knowledge framework. For example, Vidal (2011) inspected subjects' receptive knowledge of word form, productive knowledge of word meaning and productive knowledge of word knowledge. In another study, form recognition and grammar recognition was tested via multiple choice, and productive knowledge of word meaning was tested by asking participants to write down as much as they know about the meaning of the word (Zeeland \& Schmitt, 2013). It can be easily seen that receptive knowledge of word form and use, and productive knowledge of word meaning were tested in this study. Similar to this study, Teng (2018) added a fourth test to examine word collocation besides the three tests mentioned above. While Peter and Webb (2018) used form recognition, meaning recall and meaning recognition to test subjects' mastery of word knowledge. In this study, receptive knowledge of word form, and both productive and receptive 
knowledge of word meaning were tested.

It can be easily seen from these studies that way to measure word gain is still undefined today. And this undefined way to measure word knowledge will influence of the generalization of research itself and make studies less comparable if different tests are used to measure word knowledge.

Prior knowledge

Besides undefined word knowledge framework, prior knowledge, which was found to influence the effect of vocabulary acquisition, has been neglected in many studies. For example, Hulme, Barsky and Rodd (2019) explored the impact of frequency of exposures on incidental vocabulary acquisition. This study appears to be the first study to apply a more naturalistic approach, a Web-based naturalistic story-reading paradigm, to explore incidental vocabulary acquisition. But the participants were recruited through one website, whose age varied from 18 to 47. Their prior knowledge was not controlled in this study, possibly influencing the results of this study. Unlike this study, Webb and Chang (2014) selected two intact classes of similar L2 proficiency to minimise the influence of prior knowledge on results. Similarly, prior knowledge was strictly controlled in some other studies (see e.g. Chen \& Truscott, 2010; Webb, 2007).

Based on this situation, a unified word knowledge framework is in need and future studies are suggested to measure both productive and receptive word knowledge from multi-dimensions. And future studies need to control prior knowledge of participants strictly to ensure the results is reliable.

\section{Conclusion}

To sum up, from reading task to TV viewing or gaming, the study of incidental vocabulary acquisition has gone through the germination and molding period, it has come to a comprehensive development period.

From reading task to multimedia-assisted task, studies on incidental vocabulary became more adapted to technology development in contemporary society. But it does not mean that studies on reading task and listening task are out-dated. In addition, previous studies failed to apply a unified vocabulary knowledge framework, leading the results of these studies less comparable, and prior knowledge was neglected in some studies. Thus a comprehensive unified vocabulary knowledge framework is in need and prior knowledge of participants needs to be controlled in future studies into incidental vocabulary acquisition.

\section{References}

Amer, A. A. (1997). The effect of the teacher's reading aloud on the reading comprehension of EFL students. ELT Journal, 51(1), 43-47. https://doi.org/10.1093/elt/51.1.43

Bao, G. (2015). Task type effects on English as a Foreign Language learners' acquisition of receptive and productive vocabulary knowledge. System, 53, 84-95. https://doi.org/10.1016/j.system.2015.07.006

Brown, R., Waring, R. \& Donkaewbua, S. (2008). Incidental vocabulary acquisition from reading, reading-while-listening, and listening to stories. Reading in a Foreign Language, 20(2), 136-163.

Chang, L. \& Ma, J. (2018). Comparing the Effects of Listening Input and Reading Input on EFL Learners' Incidental Vocabulary Acquisition. Chinese Journal of Applied Linguistics, 41(2), 169-181. https://doi.org/10.1515/cjal-2018-0010

Chen, C. \& Truscott, J. (2010). The effects of repetition and L1 lexicalization on incidental vocabulary acquisition. Applied Linguistics, 31(5), 693-713. https://doi.org/10.1093/applin/amq031

Day, R. R., Omura, C. \& Hiramatsu, M. (1991). Incidental EFL vocabulary learning and reading. Reading in a Foreign Language, 7(2), 541-551.

Dupuy, B. \& Krashen, S. D. (1993). Incidental vocabulary acquisition in French as a foreign language. Applied Language Learning, 4(1), 55-63.

Ellis, R. \& He, X. (1999). The role of modified input and output in the incidental acquisition of word mwanings. Studies in Second Language Acquisition, 21(2), 285-301. https://doi.org/10.1017/s0272263199002077

Folse, K. S. (2006). The Effect of Type of Written Exercise on L2 Vocabulary Retention. TESOL Quarterly, 40(2), 273. https://doi.org/10.2307/40264523

Gardner, D. (2004, March). Vocabulary Input through Extensive Reading: A Comparison of Words Found in Children's Narrative and Expository Reading Materials. Applied Linguistics, 25(1), 1-37. https://doi.org/10.1093/applin/25.1.1

Gass, S. M. \& Selinker, L. (1994). Second Language Acquisition: An Introductory Course. Amsterdam: John 
Benjamins.

Hulme, R. C., Barsky, D. \& Rodd, J. M. (2019). Incidental Learning and Long-Term Retention of New Word Meanings from Stories: The Effect of Number of Exposures. Language Learning, 69(1), 18-43. https://doi.org/10.1111/lang.12313

Ina, L. (2014). Incidental foreign-language acquisition by children watching subtitled television programs. Turkish Online Journal of Educational Technology, 13(4), 81-87. https://doi.org/10.1075/btl.34.30van

Jelani, N. A. M. \& Boers, F. (2018). Examining incidental vocabulary acquisition from captioned video. ITL International Journal of Applied Linguistics, 169(1), 169-190. https://doi.org/10.1075/itl.00011.jel

Joe, A. (1995). Text-based tasks and incidental vocabulary learning. Second Language Research, 11(2), $149-158$. https://doi.org/10.1177/026765839501100206

Laufer, B. (2003). Vocabulary Acquisition in a Second Language: Do Learners Really Acquire Most Vocabulary by Reading? Some Empirical Evidence. Canadian Modern Language Review, 59(4), 567-587. https://doi.org/10.3138/cmlr.59.4.567

Mousavi, F. \& Gholami, J. (2014). Effects of Watching Flash Stories with or without Subtitle and Reading Subtitles on Incidental Vocabulary Acquisition. Procedia - Social and Behavioral Sciences, 98, $1273-1281$. https://doi.org/10.1016/j.sbspro.2014.03.543

Nagy, W. E., Herman, P. A. \& Anderson, R. C. (1985). Learning Words from Context. Reading Research Quarterly, 20(2), 233. https://doi.org/10.2307/747758

Pellicer-Sánchez, A. (2014). INCIDENTAL L2 VOCABULARY ACQUISITION from and while READING: An Eye-Tracking Study. Studies in Second Language Acquisition, 38(1), 97-130. https://doi.org/10.1017/S0272263115000224

Pellicer-Sánchez, A. \& Schmitt, N. (2010). Incidental Vocabulary Acquisition from an Authentic Novel: Do. Reading in a Foreign Language, 22(1), 31-55.

Peters, E. \& Webb, S. (2018). Incidental vocabulary acquisition through viewing L2 television and factors that affect learning. Studies in Second Language Acquisition, 40(3), 551-577. https://doi.org/10.1017/S027226311700040

Reynolds, B. L. (2015). A mixed-methods approach to investigating first- and second-language incidental vocabulary acquisition through the reading of fiction. Reading Research Quarterly, 50(1), 111-127. https://doi.org/10.1002/rrq.88

Reynolds, B. L. (2017). Evidence for the task-induced involvement construct in incidental vocabulary acquisition through digital gaming. Language Learning Journal, 45(4), $466-484$. https://doi.org/10.1080/09571736.2014.938243

Rott, S. (1999). The effect of exposure frequency in intermediate language learners' incidental vocabulary acquisition and retention through reading. Studies in Second Language Acquisition, 21(4), 589-619. https://doi.org/10.1017/s0272263199004039

Saragi, T., Nation, I. S. P. \& Meister, G. F. (1978). Vocabulary learning and reading. System, 6(2), $72-78$. https://doi.org/10.1016/0346-251X(78)90027-1

Teng, F. (2018). Incidental vocabulary acquisition from reading-only and reading-while-listening: a multi-dimensional approach. Innovation in Language Learning and Teaching, 12(3), 274-288. https://doi.org/10.1080/17501229.2016.1203328

Teng, F. (2019). The effects of context and word exposure frequency on incidental vocabulary acquisition and retention through reading. Language Learning Journal, 47(2), $145-158$. https://doi.org/10.1080/09571736.2016.1244217

Van Zeeland, H. \& Schmitt, N. (2013). Incidental vocabulary acquisition through L2 listening: Adimensions approach. System, 41(3), 609-624. https://doi.org/10.1016/j.system.2013.07.012

Vidal, K. (2003). Academic Listening: A Source of Vocabulary Acquisition? Applied Linguistics, 24(1), 56-89-373. https://doi.org/10.1093/applin/24.1.56

Vidal, K. (2011). A Comparison of the Effects of Reading and Listening on Incidental Vocabulary Acquisition. Language Learning, 61(1), 219-258. https://doi.org/10.1111/j.1467-9922.2010.00593.x

Waring, R. \& Nation, I. (2004). Second language reading and incidental vocabulary learning. Angles on the 
English Speaking World, 4, 97-110.

Waring, R. \& Takaki, M. (2003). At what rate do learners learn and retain new vocabulary from reading a graded reader? Reading in a Foreign Language, 15(2), 130-163.

Webb, S. \& Chang, A. C. S. (2015). Second language vocabulary learning through extensive reading with audio support: How do frequency and distribution of occurrence affect learning? Language Teaching Research, 19(6), 667-686. https://doi.org/10.1177/1362168814559800

Webb, S. (2007). The effects of repetition on vocabulary knowledge. Applied Linguistics, 28(1), 46-65. https://doi.org/10.1093/applin/aml048

Webb, S. (2008). The effects of context on incidental vocabulary learning. Reading in a Foreign Language, 20(2), 232-245. https://doi.org/10.1038/sj.emboj.7600273\r7600273

Wilkins, D. A. (1972). Linguistics in Language Teaching. London: Edward Arnold.

\section{Copyrights}

Copyright for this article is retained by the author(s), with first publication rights granted to the journal.

This is an open-access article distributed under the terms and conditions of the Creative Commons Attribution license (http://creativecommons.org/licenses/by/4.0/). 